\title{
EDITORIAL
}

\section{Palliative Care: We should begin to Think}

The word 'palliative' comes from the Latin 'pallium' meaning cloak. Palliative care affords relief, not cure, by concentrating on cloaking the severity of disease symptoms . World Health Organization defines Palliative Care [PC] as an approach of active total care, which focuses on the relief of physical, psycho- social and spiritual sufferings experienced by patients with life limiting illness and their families. The goal is to improve quality of life by offering comfort, promoting dignity and providing a support system in the face of incurability. PC attempts to celebrate life, even when time is limited.

Since the second half of the 20th century, world has witnessed important changes in medicine. Rapidly evolving development and high technology therapy has led to an increased emphasis to 'fight aggressively' against illness. Along with this change, there has been gradual shifting away from provision of symptom management, comfort and compassionate care ${ }^{1}$. This is particularly true when health professionals are required to care for the dying, in the face of incurability. Wellacclaimed SUPPORT study (Study to Understand Prognoses and Preferences for Outcomes and Risks of Treatments) documented these 'high technology deaths' with a futile attempt to prevent it ${ }^{2}$. Another influential report by the Institute of Medicine (IOM), published in 1997, sought to strengthen popular and professional understanding of the need for good care towards the end of life. It observed that lack of formal and proper education in palliative care, beginning from the medical school to residency and beyond was a barrier in providing the appropriate care to these patients ${ }^{3}$. Similar observations were noted in a number of editorials of globally acclaimed journals during later part of 20th century $4,5,6,7$.

The rise of PC in a modern approach took place against a backdrop of modest but growing clinical, educational and research interest ${ }^{8}$. In 1953, John Bonica published the first textbook on Pain Medicine. His groundbreaking work studied the problems of patients suffering from advanced diseases. The insights that emerged from this work strongly influenced the activities of palliative care $^{9}$. This momentum continued in the early 1960s with studies on bereavement and terminal cancer at home followed by a number of publications in reputed journals. The St. Christopher Hospice was opened in 1967 in South London by Dame Cicely Saunders. Since then, the 'era of modern palliative care' began. In 1974 Balfour Mount in Canada, first coined the term 'Palliative care' in clinical practice ${ }^{10}$. By the year 1999, there appeared $6540 \mathrm{PC}$ services in 84 countries, though mostly in developed part of the world. Whereas the number of palliative care services are increasing rapidly in affluent world, ${ }^{11}$ the extent of establishment in developing countries remain at a poor level ${ }^{12}$. Nevertheless, according to 'The Quality of Death' report, published by the Economist Intelligence Unit, it is a right denied to all but only $8 \%$ of patients who are in need of this care worldwide every year ${ }^{13}$.

All practicing doctors in any field of medical science have to look after their patients at times who have potentially life threatening illnesses. In 1998, the American college of Surgeons adopted a statement on principles guiding the surgeons at the end of life of their patients. This guideline incorporates almost all the principles of PC including provision of access to organized Palliative Care service. A group of surgeons was convened in 2001 to put these principles into operation and to introduce the percepts and techniques of PC into surgical practice and education.

A subset of surgical PC, palliative surgery has been recently defined which includes surgical procedures even with curative intent. In surgical oncology it plays an important role, e.g. in breast cancer requiring mastectomy, a bypass operation in inoperable colonic or biliary malignancies. Resections of hepatic or pulmonary secondaries, along with other 'therapies' are good examples of palliative procedures ${ }^{14}$

Principles of palliative care are within the larger primary goals of medicine. ${ }^{15}$ 
These are:

- to Restore function of patients as normally and for as long as possible,

- empathic listening and providing all honest informations,

- to ensure patient or patients' family know who to call if things go wrong,

- to appreciate that many choose home, but some hospitals for their care,

- to be aware of different cultural practices and religious beliefs,

- to be aware of how looking after seriously ill patients can affect heath care workers.

In developing countries, an estimated 27 million people would benefit from PC and this number is growing fast. Improving PC service would not require large money or restructuring of healthcare system. There are remarkable success stories of Palliative care in the developing world as in Kerala and Uganada ${ }^{15}$.

Extent of the problems in Bangladesh: More than a million people die in Bangladesh every year. Approximately 0.6 million of them are estimated to be in need of PC service. More than $4 \%$ of the population are aged 65 and above and the number of elderly are on a steady rise. Most of these people are in need of care routinely offered by a palliative care services. While planning such services here, several factors like low income, limited academic link in health education, natural calamity, mismanagement of resources, and false belief etc. need special consideration. The positive side is our success stories of prophylaxis against common diseases, better health awareness, wide service delivery network even in villages, use of safe drinking water and many more.

To ensure that PC is available and accessible to the majority of the needy, a community-based approach should get appropriate consideration. It is essential that the doctors and other health care providers be educated with knowledge, technical skill and attitudinal motivation for dealing with these patients in a systemic manner. Opportunities for research in Palliative Medicine, like every subject, should be identified.

PC embodies the essential features of all good care to be attained through multidisciplinary or interdisciplinary approach. It is to be offered with all other medical treatments. Recently, Bangabandhu Sheikh Mujib
Medical University has opened this chapter of Palliative Care, which is a step ahead in our country. The endeavor needs to be appreciated and acknowledged.

The authors do believe, 'let there be light'.

(J Bangladesh Coll Phys Surg 2011; 29: )

A.K.M Mahbubur Rahman ${ }^{\mathrm{a}}$, Nezamuddin Ahmad ${ }^{\mathrm{b}}$

a. Honorary Professor, Surgery, WMC\&H, Uttara, Dhaka.

b. Professor \& Project Coordinator, Palliative Care Service, BSMMU, Dhaka

\section{References:}

1. Cassel E J (1982). The nature of suffering and the goals of medicine: N Eng J Med; 306 : 639 -645

2. The SUPPORT Principal Investigators (1995) A controlled trial to improve care of seriously ill hospitalized patients: the study to understand prognoses and preferences for outcomes. JAMA 274 (2) : 1591-1598

3. McCarthy M (1997) US patients do not always get the best end of life care. The Lancet ; 349: 9067 :1747

4. Editorial (1997). Time for education in Palliative Care, The Lancet; 349: 9067: 1709.

5. Kenyon Z.(1995) Editorial: Palliative care in general practice.British Medical Journal; 311:888-889

6. I Higginson(1999) Editorial: Evidence based palliative care: British Medical Journal; 319:462-463

7. Margaret A. Winker A.(1999), Caring for Patients at the End of Life (editorials) JAMA, 24; 282: 20196

8. Clark, D 2002).Between hope and acceptance: the medicalisation of dying. British Medical Journal; 324: 905-7.

9. Clark. D (2009) International progress in creating palliative Medicine as a specialized discipline. In Oxford Text book of Palliative Medicine ( $4^{\text {th }}$ ed) eds. Geoffrey Hanks and Nathan Cherny. Oxford University press

10. Mount B (1977).The Royal Victoria Hospital palliative care service: a Canadian experience. In Hospice Care on the International Scene (eds.C Saunders and R. Kastenbaum) Springer, New York.

11. Centeno C, Clark D, Roccafort J, Flores LA et al. (2006) The map of specific resources of palliative care in Europe. Palliative Medicine; 20:316

12. Bruera E, Sweeney C (2002). Palliative Care models: International perspective. J Palliative Medicine; 5: 319-43

13. Painfully slow progress on palliative care (2010) Editorial the lancet 376; 24

14. Daniel B, Hinshaw G, P Dunn (2009) Special issue on Palliative Surgery. Editorial. Progress in Palliative Care 17; 5:235-236

15. Kumar, S (2004). Learning from low-income countries: what are the lessons? Palliative Care can be delivered through neighborhood networks. British Medical Journal. 329; 1184 